\title{
The Prevalence and Limitations of Electronic Charts in University Flight Training
}

\author{
Tyler A. Babb \\ Middle Tennessee State University
}

\begin{abstract}
The use of electronic charts in pilot training has greatly increased in the last several years. UAA member universities continue to instruct using paper navigation charts, as these are still used for training and have not significantly changed in decades. However, the aviation industry has embraced electronic charts in the cockpit. Many airlines, charter companies and fractional operators have already transitioned to electronic charts. This study had two main research questions: (1) how commonly are electronic charts being used by pilots in university flight training, and (2) what are the benefits and limitations of electronic charts are as identified by students using electronic charts? A total of 84 professional pilot students were surveyed at a UAA member university. The majority of students surveyed indicated that they used electronic charts. Specific data was gathered on types of devices and software used, limitations of the devices and software, and pilot attitudes toward this new technology. Student attitudes toward the use of electronic charts were found to be generally positive.
\end{abstract}

\section{Introduction}

Airlines, charter companies, fractional operations and flight schools are all seeing a trend toward the use of electronic flight bags. Electronic Flight Bags (EFBs) perform many functions for current professional pilots including the essential function of providing electronic chart data. As of June 24, 2013, American Airlines had implemented electronic flight bags and completely replaced paper charts on all of its aircraft, and the airline plans to implement electronic chart use for their regional carrier, American Eagle, as well (American Airlines, 2013). Airlines such as Jet Blue Airways and U.S. Airways are also transitioning to electronic charts in the cockpit (Moorman, 2013). Current pilots in training thus have an increasing chance of using electronic charts in their future professional flying careers.

As operators have implemented electronic charts, flight schools have responded by using tablet computers such as iPads not only to view charts but to enhance training. Flight schools are collaborating with avionics distributors to fully integrate tablets into flight training. Ray Swanson is the vice-president of distribution and avionics for Tecnam North America. Mr. Swanson believes that affordable tablet computers will become a cornerstone of flight training, and the flight training industry can use tablet computers for flight 
planning, enhancing instruction/reference materials, and tracking student progress (Croft, 2010).

As other flight schools are building programs to support electronic charts, university pilot training programs should create programs as well. University Aviation Association member universities are "remaining on the forefront of technology innovations" (Arch \& Sherman, p.18, 2006). If the pilots enrolled in these programs are using electronic charts, the universities should be aware of this and develop programs as other flight schools have. The purpose of this study was to find out how many professional pilot students are using electronic charts at a particular UAA university and to identify the limitations of the electronic charts as identified by the participants.

\section{Literature Review}

Understanding the benefits of electronic chart usage provides a background as to why they have become so popular. Financial benefits are always desired by operators and flight schools. The companies that provide electronic charts are confident in the affordability of their product. ForeFlight mobile is a common electronic chart provider and provides electronic charts to the U.S. Coast Guard, Flight Options, and Frontier Airlines (Berrett, 2014). The CEO of Foreflight Tyson Weihs stated that, "One customer alone saved more than $\$ 16,000$ annually in printing and overnight shipping costs" (Berrett, 2014, 96). For operators, implementing electronic charts is simply good business.

If a technology can be implemented efficiently in the cockpit then pilots themselves feel safer. In a recent study on pilots adapting to Technically Advanced Aircraft (TAA), regional airline pilots and instructors were asked about pilots' ability to interpret TAA technology in the cockpit. The concern was that pilots who had not seen or flown TAA aircraft would have trouble adjusting to the technology in the cockpit when hired by the airline. The majority of pilots and instructors surveyed (85\%) "...agreed that using advanced technology made a safer pilot" (Renzo \& Bliss, p.48, 2010). Electronic chart technology has been developed and integrated much like TAA. Electronic chart technology could enhance flight safety.

As with any technology, reliability is a major concern. The devices used to perform advanced functions in the cockpit must be trusted by the pilots that use them. In order to fully trust a technology, the pilot must believe that the technology or system is reliable. If the systems provide reliability, the operator (pilots) will be more likely to trust the system (Bhana, 2010). Not all technology is flawless, and the trends of reliability for devices and software must be observed by pilots in order to truly trust any new technology.

Classroom technology has progressed with the industry technology. In a study of UAA member universities, the issue of classroom technology matching industry technology was closely observed (Arch \& Sherman, 2006). This research involved an online survey of thirty-four UAA member universities and focused on Technically Advanced Aircraft 
(TAA), and the use of classroom technology and software. In their research, they found that "the majority of UAA respondents felt that technology is very important in the classroom, aircraft, and department/student support systems" (Arch \& Sherman, p.18, 2006).

The implementation of available technology is growing at an increasing pace. This trend will continue to present significant challenges for the aviation community (FAA, 2006). It is the responsibility of universities and the FAA to train and regulate these technologies as they become the industry standard. As for educators, we must remain capable of teaching these new technologies properly as they arise. Joe Clark of EmbryRiddle Aeronautical University stated, "How we initially teach our students to fly and use automation will stay with them for a lifetime" (Clark, p. 20, 2014). It is critical that these students receive complete initial instruction on these technologies to become safe and efficient professional pilots in the future.

There are many factors that influence the prevalence of electronic charts, including the costs associated, the level of training (certificate), and the student's willingness to trust the technology. As electronic charts are more commonly used for training, new complications may develop due to the nature of the devices used to view the charts. This research focused on the prevalence and limitations of the devices and the technology as used for training at a UAA member university.

\section{Methodology}

A paper survey was completed by current pilots in training at a UAA member fouryear aviation university. The survey consisted of a total of 25 questions including yes/no, yes/not sure/no, and Likert scale answers. One of the purposes of the research was to determine if the total flight time or ratings acquired by the pilots had any effect on the usage of electronic charts. Thus, the pilots were asked for total flight time and ratings earned. There were no other demographical data collected to identify the participants. As required by the UAA member university's IRB requirements, the students were encouraged but not required to participate in the survey. The informed consent process included both a verbal consent to participate and paper documentation of consent as well. The university's IRB approval protocol number was 14-327.

\section{Limitations}

The research included pilots from all stages of training from student pilots to instrument instructors. The pilots' knowledge of VFR and IFR charts and limitations became apparent during the survey process. For example, some student pilots were currently using only VFR charts on software that provided both VFR and IFR charts. These pilots were not sure about the coverage areas and limitations of electronic IFR charts. These pilots in training may 
need to access only VFR information so that they access charts applicable to their current training.

This research was limited due to the fact that the survey population was relatively small. Also, the participants were all enrolled at one university. Though not all university students are recent high school graduates, the majority of the participants were fairly young and thus more comfortable with the daily use of similar electronic devices.

\section{Participants}

This research involved surveys of 84 professional pilot students at the survey university. The pilots that completed the survey were enrolled in one of the following courses: (1) a private pilot ground course, (2) an instrument ground course, (3) a commercial/multi engine rating ground course, (4) a navigation course, or (5) a flight instructor ground course during the spring semester of 2014. The participants' pilot certificates ranked from Private Pilot to Flight Instructor-Instrument.

\section{Materials and Procedure}

The survey was completed on paper to encourage timely participation and simplify the survey process. During the spring 2014 semester, the printed surveys were distributed during the class time of the five previously mentioned aviation courses. All surveys were completed within a three week period. The survey included 25 questions including both qualitative and quantitative data to solicit specific information on the devices, software, and pilot thoughts on electronic charts.

It is apparent that future airline pilots have a high chance of seeing these systems in the cockpit one day. Participants were asked whether or not they expect to use electronic charts during their professional flying careers. Also, in order to determine how common electronic chart usage is among pilot students, a series of survey questions asked for details on their usage. Not all participants used electronic charts. The students that used electronic charts were asked additional questions to determine the extent of the usage, coverage areas, and type of uses (i.e. VFR, IFR). These participants were also asked questions referring to their particular devices and software.

Participants that currently used electronic charts were also asked about complications with the charts. The devices used and the software used can create issues with chart accessibility in flight. Survey questions asked if they carried backup charts, and if they had any way of charging their device during flight. The participants that did not use electronic charts were asked a series of questions regarding why they did not use electronic charts and what their comfort level would be transitioning to electronic charts in the future. 


\section{Results}

Of the five classes surveyed, there were 84 participant responses. The highest rating obtained by each participant can be seen in Table 1 below. The participants included pilots at all levels of training. Two of the participants did not indicate their highest pilot rating.

Table 1

Survey Participation Numbers with the Highest Pilot Ratings Obtained by Participants

\begin{tabular}{lc}
\multicolumn{1}{c}{ Rating } & Number of Surveys \\
\hline Student Pilot & 21 \\
Private Pilot & 16 \\
Instrument & 16 \\
Commercial & 9 \\
Multi Engine & 10 \\
CFI & 4 \\
CFII & 6 \\
MEI & 0 \\
\hline Total & 82 \\
\hline
\end{tabular}

Total flight time data was also collected. This data was collected separately from rating information as not all pilots acquire particular ratings at a set number of total flight hours. The total flight time for each participant is shown in Table 2. Nearly half of the participants $(46 \%)$ had between 100 and 250 hours of total flight time logged.

Table 2

Survey Participation Numbers as Indicated by Total Flight Time of Participants

\begin{tabular}{lc}
\multicolumn{1}{c}{ Total Hours } & Number of Surveys \\
\hline $0-25$ & 5 \\
$25-50$ & 18 \\
$50-100$ & 11 \\
$100-250$ & 39 \\
$250-500$ & 9 \\
More than 500 & 2 \\
\hline Total & 84 \\
\hline
\end{tabular}

The affordability of navigation charts affects all pilots during training. An early survey question asked "Do you think a professional pilot student could save money if that person bought both a device and a chart subscription instead of paper charts during their training?" This question was asked to all participants regardless as to whether the applicant used electronic charts. Of the 84 total participants, 79\% responded "yes," 11\% responded "not 
sure," and 10\% responded "no." This data is reflected in Figure 1. Only $10 \%$ of the participants believed that electronic charts were more affordable than paper charts.

\section{Could Pilot Students Save Money by Using Electronic Charts?}

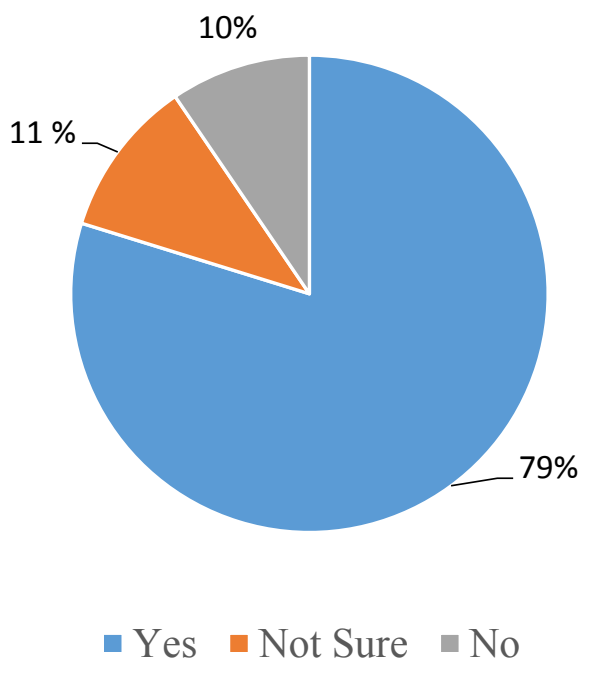

Figure 1. Professional Pilot Student Perceptions of the Affordability of Electronic Charts and Paper Charts

Another early survey questions was asked to establish how familiar the student was with small touch screen devices which are commonly used to view electronic charts. When asked "Have you ever used a tablet computer (or similar touch screen device)?" $95 \%$ of the respondents replied "yes," and only $5 \%$ of the participants replied "no." The overwhelming majority of the pilots interviewed had used a tablet computer or similar touch screen device at some point prior to the survey.

To determine student perspective on the future use of electronic charts in the industry, all participants were asked "Do you expect to use electronic charts in your professional flying career?" As shown on Figure 2, 93\% of participants responded "yes," five percent of participants responded "not sure," and two percent of participants responded "no." 
Do you expect to use electronic charts during your professional flying career?

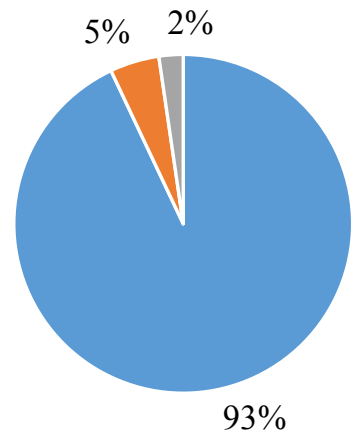

$\square$ Yes $\quad$ Not Sure $\quad$ No

Figure 2. Student Perceptions on the Prevalence of Electronic Charts in Future Professional Pilot Positions

The prevalence of electronic chart usage was one of the main purposes of this research. To determine the current prevalence of professional pilot student electronic chart usage, the question "Do you use electronic charts?" was asked. Of the total 84 participants, $81 \%$ replied "yes" as displayed in Figure 3.

\section{Professional Pilot Student Electronic Chart Usage}

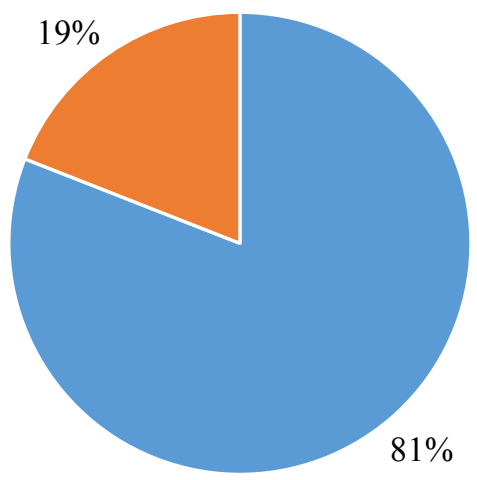

- Currently Use Eelectronic Charts $\quad$ Currently Do Not Use Electronic Charts

Figure 3. The Current Prevalence of Electronic Charts with the Participant Group 
Because each participant had indicated their current hours, the data collected from each survey was used to determine if total flight hours were a factor in the use of electronic charts. As the total times progressed from zero to 100 hours, the data indicates that the usage grows significantly. The percentage of participants which used electronic charts based upon total flight time is depicted in Table 3.

Table 3

Participant Electronic Chart Usage According to Total Flight Time

\begin{tabular}{ccc} 
Total Hours & $\begin{array}{c}\text { Number of } \\
\text { Participants }\end{array}$ & $\begin{array}{c}\text { Percentage of Participants } \\
\text { that used electronic charts }\end{array}$ \\
\hline $0-25$ & 5 & $20 \%$ \\
$25-50$ & 18 & $66 \%$ \\
$50-100$ & 11 & $82 \%$ \\
$100-250$ & 39 & $92 \%$ \\
$250-500$ & 9 & $89 \%$ \\
More than 500 & 2 & $100 \%$ \\
\hline
\end{tabular}

After establishing which participants used electronic charts, the survey collected more specific data about the sources of the charts. Participants were asked "What type of application or software provides the charts to you?" As displayed in Figure 4, 94\% of the pilots who use electronic charts used ForeFlight Mobile. Other providers included Garmin Pilot, Jeppesen, and fltplan.com, each with one response.

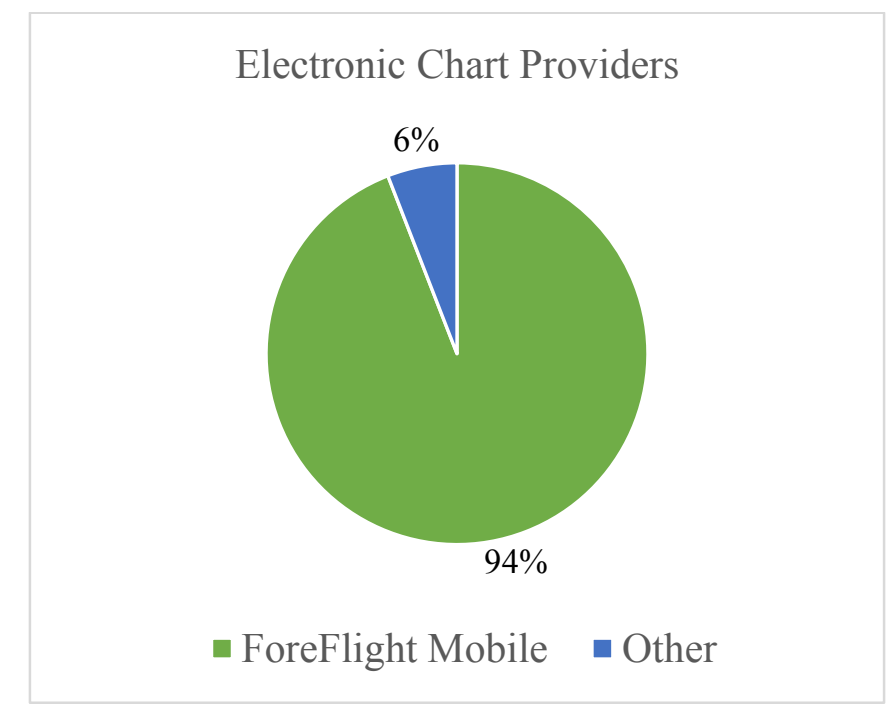

Figure 4. Sources of Electronic Charts for Professional Pilot Students Actively Using Electronic Charts 
All of the chart information must be FAA approved and current. The FAA has long been providing paper charts to pilots, and in the future the FAA may provide electronic charts directly to the pilot. The subsequent survey question asked "If the FAA were to provide electronic charts, would you use those instead of your current provider?" Of the total eighty-four participants, 51\% responded "yes," 39\% responded "not sure," and 10\% of the participants responded "no."

Electronic charts are currently provided for VFR and IFR purposes. To determine the prevalence of both types of usage, the participants were asked "Do you use electronic charts for VFR charts?" The corresponding coverage areas were also collected. Of the 68 applicable participants, 91\% used electronic VFR charts. Of those responses, 58\% had access to VFR charts for the entire contiguous U.S., and $29 \%$ of the respondents had access to VFR charts in the local region.

The following survey question asked "Do you use electronic charts for IFR Charts?" The corresponding coverage areas were also collected. Of the applicable 68 participants, $79 \%$ indicated that they use electronic IFR charts. Of those 54 responses, $57 \%$ indicated that the IFR charts available to them covered the entire U.S., and 30\% indicated that their IFR chart subscription covers the local region only. The majority of participants that used electronic IFR charts had coverage of the entire contiguous U.S.

The type of device used to access electronic charts is another important factor. The participants were asked "What type of device do you use for electronic charts?" Figure 5 indicates that the Apple iPad was the most common device and was used by 62 of the 68 electronic chart users (91\%). This data included multiple versions and sizes of the iPad. Other responses included the Nexus 7, the Samsung Galaxy Tablet, the Kindle Fire, and the iPhone, each with one response.

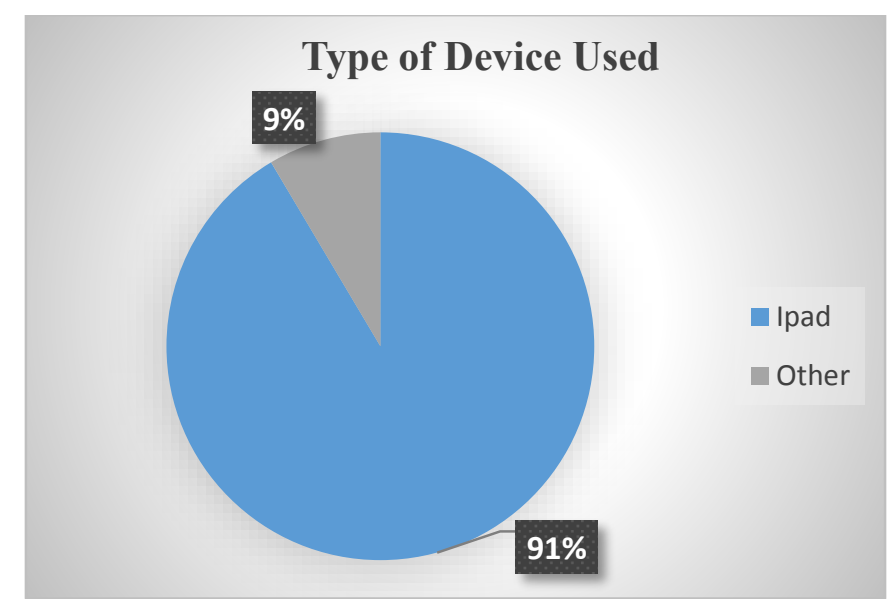

Figure 5. Types of Devices Used in the Cockpit for Electronic Charts 
The size of the device is another factor to consider, as a small screen may fit better in the cockpit, but may require more work from the pilot to scroll across sectionals and/or IFR low enroute charts. The participants were asked "If it were acceptable to the FAA, would you be comfortable using your mobile phone to access essential navigation information?" Of the eighty-four participants, $60 \%$ of the responses indicated "yes," $13 \%$ replied "not sure," and 27\% replied "no."

As far as the size of the device, the underlying issue is that of visibility and chart usage. Pilots are constantly trained on limitations. The limitations of electronic charts not only include the coverage areas but also the usability and dependability of the devices in flight. The participants that used electronic charts were asked "Have you ever had complications with accessing electronic charts in flight?" If the participant responded "yes", then that person was asked to provide details about the occurrence. Not all participants that answered "yes" provided details of the event.

Of the 68 applicable participants, 33\% reported some type of complication while the charts in flight. The types of complications included overheating, lack of current or applicable charts, loss of $3 \mathrm{G}$ or $4 \mathrm{G}$ connectivity, battery failure, screen glare, and application crashes. An "other" option with an open response was provided, but zero participants indicated "other". This data is summarized in Table 4.

Table 4

Reported Complications of Electronic Chart Usage for Pilot Participants

\begin{tabular}{lc} 
Type of Failure & Number of Reported Complications \\
\hline Overheating & 6 \\
Current/applicable chart not downloaded & 3 \\
Loss of 3G/4G service & 2 \\
Battery failure & 2 \\
Screen Glare & 1 \\
Application crash & 1 \\
\hline
\end{tabular}

As a pilot gains more experience, the total time using electronic charts could increase the chances that the pilot will have encountered a complication with the charts. With the total times and complication rates collected, the data indicates the chances of the participants experiencing these complications based upon total time. As shown in Figure 6 , the more flight time a pilot has does in fact increase the chances of that pilot having complications with electronic charts. It is important to note that the amount of total flight time using electronic charts was not collected. 


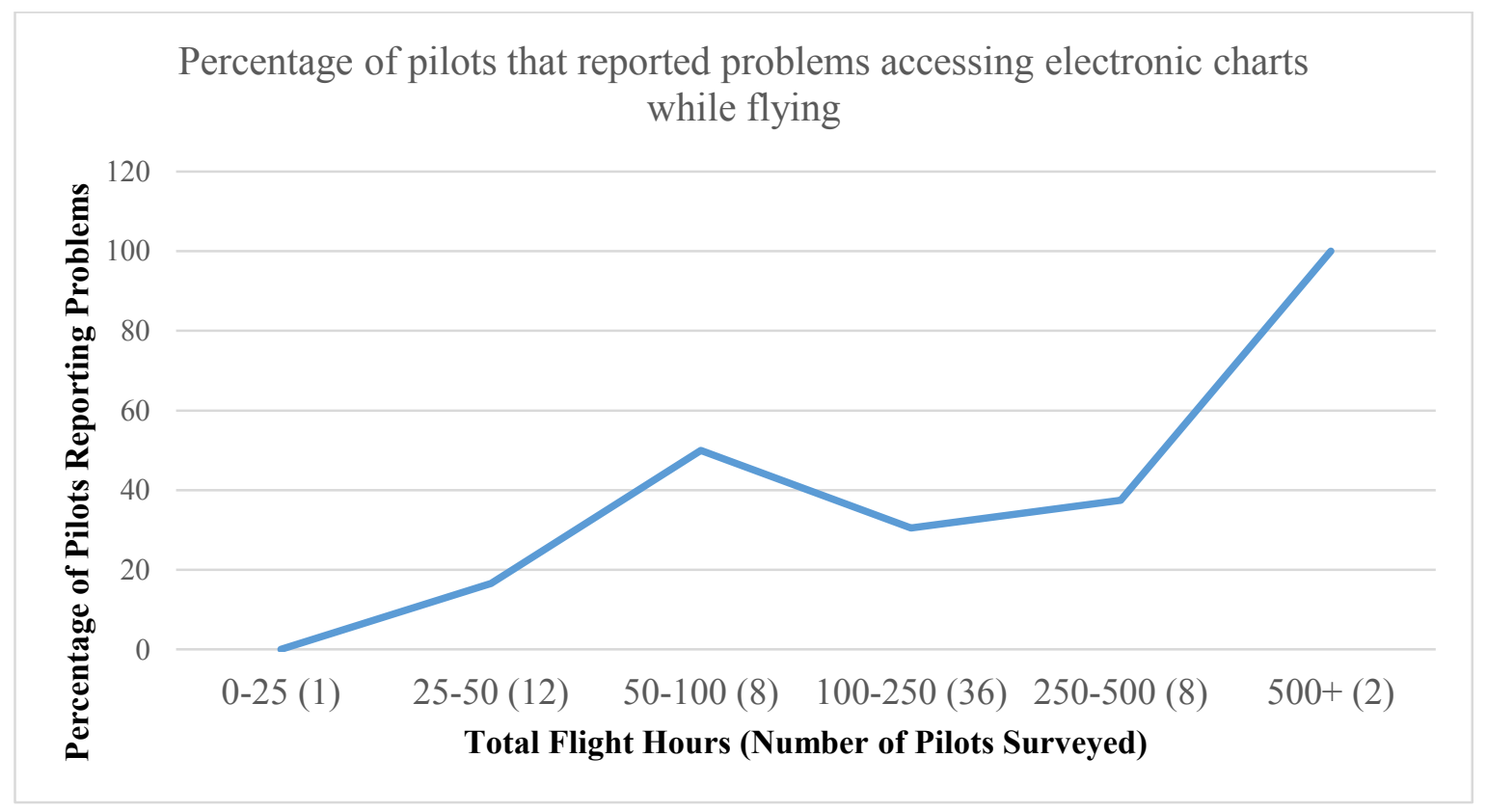

Figure 6. Percentage of Reports of Complications with Electronic Charts for Participants Based Upon Total Flight Time

Overheating of the devices was reported as the most common complication. The second most common complication was the lack of either a current chart or the applicable chart for a particular flight. Battery life and the loss of $3 \mathrm{G} / 4 \mathrm{G}$ service in flight were equally reported for the third most common complication for accessing electronic charts while in flight.

Battery life for the device itself is critical when considering the usability of the device. As previously shown in Table 4, battery failure was a common complication of electronic charts. The participants that used electronic charts were asked "Do you have any way to charge your device during flight?" Of the applicable participants, 62\% indicated "yes," $37 \%$ responded "no," and 1\% responded "not sure," as indicated in Figure 7.

Due to the possibility of electronic chart complications and battery limitations, pilots should consider carrying backup charts. Redundancy is a common theme in aviation, from two magnetos to two engines and now to two charts. It is important to note that the following data was gathered from both pilots that fly with only electronic VFR charts as well as pilots that fly with electronic VFR and IFR charts. 


\section{Can You Charge Your Device During Flight?}

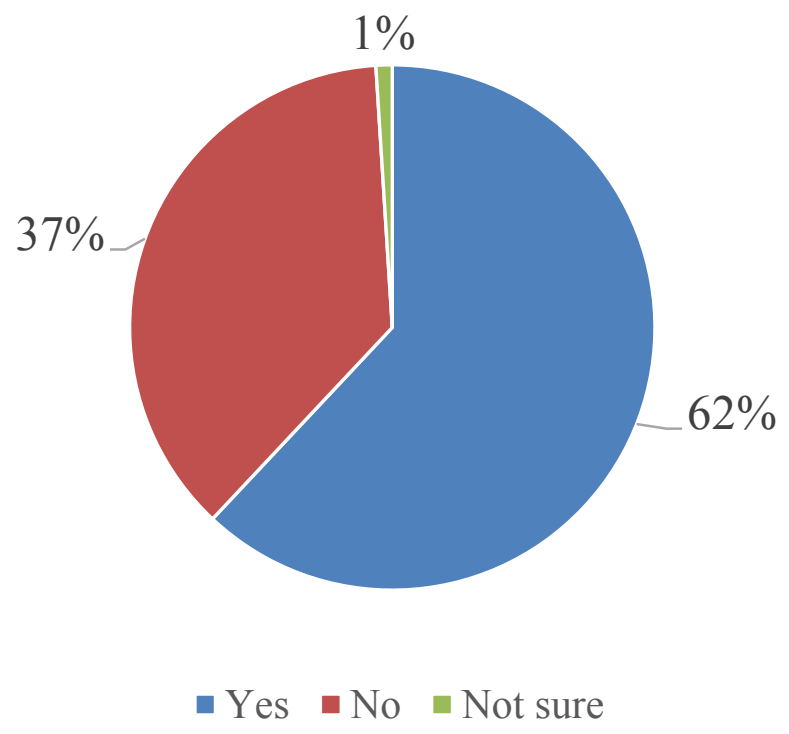

Figure 7. Device Charging Capability in Flight by Pilots Using Electronic Charts

Pilots that used electronic charts were asked if they fly with backup charts of some type. Information from the applicable participants indicated that $36 \%$ always carried backup charts, $47 \%$ sometimes carried backup charts, and $17 \%$ never carried backup charts. This data is presented in Figure 8.

After discovering how often backup charts were carried, the survey then asked if the backup charts were either paper or electronic. Data from the participants who used electronic charts indicated that $26 \%$ of these students carried paper backup charts. Electronic backup charts were more commonly used, as $68 \%$ percent of those pilots that carried backup charts were carrying electronic backup charts.

Not all of the participants used electronic charts. If the student did not use electronic charts the survey then instructed these participants to skip to the questions concerning why they did not and how they felt about the electronic charts. Only 19\% of the survey participants indicated that they did not currently use electronic charts in the cockpit.

Pilots that used only paper charts were asked "Why don't you use electronic charts?" The options on the survey were (1) paper charts were thought to be less expensive, (2) the participant did not own a capable device, (3) the participant preferred paper charts, (4) the participant was concerned with losing or damaging a device, and (5) the participant's initial chart training was with paper charts. There was also an option for "other" but zero participants responded "other". Figure 9 summarizes the responses. 
You use electronic charts. Do you fly with backup charts?

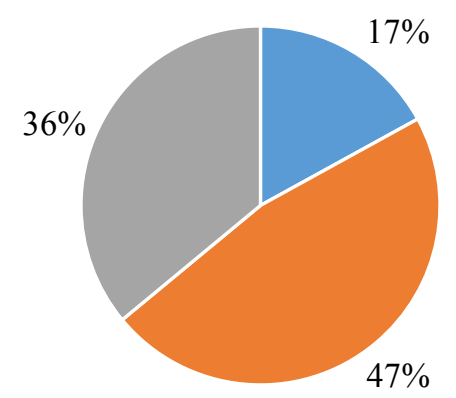

- Never - Sometimes " Always

Figure 8. How Often Participants who Used Electronic Chart Carried Backup Charts

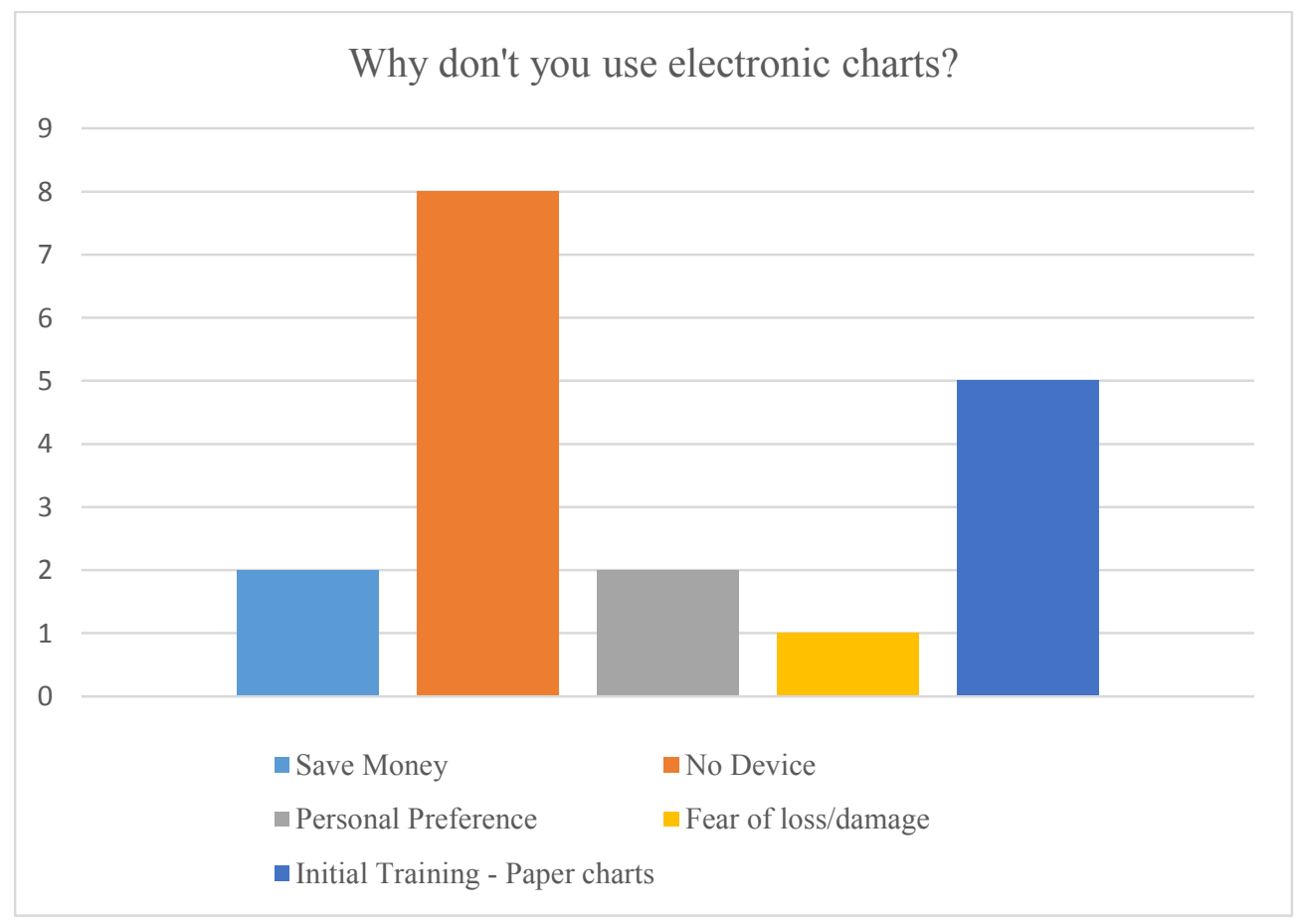

Figure 9. Reasons Why Some Surveyed Pilots Did Not Use Electronic Charts

The final question of the survey was an open ended question asking the participants' thoughts and concerns pertaining to the use of electronic charts in flight. All participants were asked to provide feedback, but not all participants answered the question. The most common concern was that of battery life and the pilot losing access to charts during flight. 
This was reported by $15 \%$ of the participants. The second most common concern dealt with failure of either the application or the device (separate from battery failure). Failure of the device or application was also reported by $12 \%$ of the participants. The third most common concern dealt with the pilot desiring or needing some form of backup charts. Eight participants $(10 \%)$ responded with this concern.

Participants also responded with their positive feedback on electronic charts. This data was gathered from all 84 participants, of which 21 of the total participants $(25 \%)$ indicated that electronic charts were easier or more efficient than paper charts. Also, 15 participants (18\%) indicated that electronic charts helped improve cockpit effectiveness and/or use less space in the cockpit. Six of the participants (7\%) indicated that updating the charts was easier with electronic charts than it would be with paper charts.

\section{Discussion}

The participants for the survey were diverse in terms of pilot rating. Many of the participants $(25 \%)$ were student pilots. Each rating from student pilot through multi-engine pilot had at least ten participants. This indicates that the majority of survey participants were pilots in training somewhere between student pilot and multi engine pilot.

Most of the participants (46\%) had somewhere between 100 to 250 hours of total flight time logged. There were participants from each category from zero to 25 hours and participants with more than 500 hundred hours. This indicates that the survey collected data from pilots that are beginning training as well as pilots who are now providing training to others.

The majority of participants indicated that they believed that a pilot in training could save money by purchasing both a device and an electronic chart subscription as opposed to purchasing paper charts. To further investigate this issue, a simulation was developed to discover exactly how the cost of electronic charts compares to that of paper charts. If a pilot owns a capable device, the cost of the electronic charts is very competitive with the cost of paper charts.

Assuming that a student pilot (private student) progresses well and earns his or her private pilot rating within six months, that pilot would purchase paper charts including the items shown in Table 5 (Sportsman's Market, 2014). Regardless as to what type of charts a pilot uses, it is critical that the pilot maintain current air navigation charts for flying purposes. With the addition of electronic charts, it can now be determined what the costs are for these charts in the paper and electronic versions. 
Table 5

Paper Chart Expenses for a Private Student Over a Six Month Period

\begin{tabular}{lc}
\multicolumn{1}{c}{ Item } & Cost \\
\hline Sectional Charts (2) & $\$ 18.00$ \\
Plotter (1) & $\$ 6.00$ \\
AF/D (3) & $\$ 15.90$ \\
6 month total & $\$ 39.90$ \\
\hline
\end{tabular}

In a six month period, the average private student pilot will spend about $\$ 40$ on charts, so a full year of current paper charts would cost nearly $\$ 80$ plus any applicable shipping costs. For flight planning purposes with paper charts, the student would need to buy a VFR navigation plotter.

ForeFlight subscriptions cover all of the data these paper charts do, last for one year, and the standard version costs $\$ 75$ (ForeFlight Mobile, 2014). Thus, the effective cost of the VFR electronic charts is nearly identical to the cost of VFR paper charts, assuming that the pilot has access to or owns an electronic device capable of using a current version of the electronic chart software.

Only $10 \%$ of the pilots that participated thought that electronic charts would be cheaper than paper charts even if a device was included in the cost. Pilot students are subject to buying numerous charts and other equipment, and the cost of charts can add an additional economic burden for pilots in training. In order to use electronic charts, a pilot must first have access or own a device on which to view the charts. These can get expensive, and as a new student pilot it can be intimidating to consider purchasing both a device and an electronic chart subscription. Current versions of the iPad start at $\$ 499$ (Apple, 2014). The age of the device becomes an issue as well because software updates may require certain capabilities of your device and if the device ages, it may have software problems or be incapable of running the software. For example, the latest version of ForeFlight Mobile requires Apple iOs7, which cannot be operated by the original Apple Ipads (ForeFlight, 2014).

The vast majority of participants $(95 \%)$ had used "a tablet computer or similar touch screen device" at least once before in their lifetimes. Touch screen devices have spread from personal cellular phone use to buying groceries on a daily basis. The ability to use these devices and understand the limitations of these devices should be included in current pilot training.

Most of the pilots indicated that they expected to use electronic charts during their professional flying career. Many of the pilot students at universities will go on to work for the regional and/or major airlines. However, not all pilots intend to work as airline pilots. 
This could indicate why some students did not expect to use electronic charts in their professional flying career.

The majority of pilots surveyed used electronic charts. This was evident even at the "student pilot" level, indicating that some student pilots' first experience of planning true course, wind correction angles, ground speeds, and magnetic variation were all being supplied automatically by the software, as opposed to be interpreted accurately by the pilot using paper charts, a plotter and an E6B. This information brings up a critical point that aviation educators and flight instructors must now consider: should electronic charts be used for primary (original) flight planning education/training? More research is suggested in this area.

As a pilot's flight time increases, the survey indicates that the use of electronic charts is more common. This may be linked to the fact that a number of the private students are using paper charts and then transitioning to electronic charts during instrument training. Accessing and organizing instrument approach plates with a tablet computer was reported to be much easier than accessing the charts on paper.

Ninety-four percent of electronic chart users used the ForeFlight Mobile software. ForeFlight is a common provider and the standard subscription covers all of the data a pilot would otherwise have with a paper sectional chart and the paper airport/facility directory publication. The standard subscription to ForeFlight includes electronic FAA VFR sectionals, DOD/FAA terminal procedures, Airport/Facility Directory (A/FD) information, and IFR enroute charts. The software or application can work on a smart phone or a tablet computer and provides charts in the FAA/ NOAA format.

The effective date of navigation charts is always a concern to pilots. Current charts must be on board the aircraft to satisfy FAR 91.103: Preflight Action. The Federal Aviation Regulation requires that the pilot must be familiar with "For any flight, runway lengths at airports of intended use" (FAA, 2014). Historically pilots have had to purchase new paper charts as the charts are updated and check NOTAMs for changes to the information and/or procedures. Software such as ForeFlight mobile streamlines this process and updates the charts at the push of a button.

There may come a day when the FAA is distributing electronic navigation charts directly to the pilots without any outside commercial delivery. If the FAA were to offer electronic chart subscriptions directly to the pilots, then in theory the software subscription would become more affordable to the user. The survey participants were mixed in their opinions as to whether they would use FAA electronic charts as opposed to their current chart provider.

Participants were asked about using electronic charts for VFR and IFR purposes. The majority of the students which used VFR charts also used electronic charts for IFR purposes. Due to the common use of ForeFlight mobile for the participants surveyed, the 
majority of the participants had access to VFR and IFR charts for the entire contiguous U.S. area. The pilots using these charts must be familiar with the coverage areas and the currency of each coverage area on their devices as required by FAR 91.103.

As indicated on Figure 5, the majority of students (91\%) using electronic charts were using some type of Apple iPad device to access chart information. The Apple iPad is a common device used by airline pilots as well. Jet Blue Airways has been operating with electronic charts since they began flying in 1998, but recently has transitioned to the use of the Apple iPad (Moorman, 2013). The research data included iPads of all types, including the iPad Mini which has a smaller screen than other iPads.

Most of these devices are not nearly as large as a VFR sectional chart, but are close to the size of a typical instrument terminal procedure or approach. The software allows for the pilot to zoom in and out of enroute charts and sectionals, but this task becomes more difficult with a smaller screen. The survey respondents were mixed in their opinions and comfort level of using a small device such as a smart phone to access critical chart information. Most smart phone screens are smaller than tablet screens and would thus be more difficult to use in the cockpit. The essential question is "Can the pilot view and interpret data by the device?" The FAA does not currently have a policy/regulation on the size of device, and for now it seems that this issue is up for individual FAA inspector scrutiny.

If a pilot is going to use a tablet computer or any electronic device to access critical navigation information, that person must be aware of the limitations of that device. Overheating of the devices was the most common complication reported. Pilots should be careful to store these devices in cool areas and to verify that when not in use, the device is in fact in "sleep mode" or shut down and consuming as little battery as possible.

Pilots should consider the battery life of the unit and how long it would last during a flight in addition to the currency and coverage area of the chart subscription. If the device is connected to a $3 \mathrm{G} / 4 \mathrm{G}$ wireless connection and is constantly providing "geo-referenced" data (position information) during flight, the battery will drain faster. However, if the pilot is simply using the device to look at static information such as a saved approach plate, the battery would then last longer. The use of the device heavily influences the battery life. Additional research is suggested in this area.

Pilots using electronic charts must know how to conserve battery power. For example, if a pilot were to reference a chart half way through a three hour flight and then set the device down, the device may still be providing data while not being used. Once at the destination, the pilot could pick up the device only to find out that the battery has drained completely, creating a potentially serious scenario.

If a Private Pilot was flying on a VFR day and lost his/her electronic VFR charts while cruising in a sparsely populated area, that pilot could probably manage to get the aircraft 
on the ground safely. But if it were an IMC day and an IFR pilot flying in actual instrument conditions, planning to use the device for the approach at the destination, a device failure could cause a serious scenario. Hopefully the pilot would have checked during preflight to see if the destination airport had PAR or ASR capabilities to allow for a safe IFR approach and landing.

The pilots that used electronic devices were asked if they had any way of charging that device in flight. With this question, two things must be considered: (1) an aircraft with a suitable electrical outlet could charge the device for the entire flight as long as the aircraft electrical system is operating normally, and (2) external battery packs which could provide a charge in case of an emergency, and are adequately charged prior to each flight. There were 68 pilots surveyed that used electronic charts surveyed. The majority of the participants $(63 \%)$ had some way of charging the device during flight. Less than half of the participants $(37 \%)$ did not have any way to charge the device during flight. Not all aircraft are exactly alike, so in some cases the pilot could charge his or her device in one specific aircraft but not another. It is essential that the pilot knows if he or she can charge the device during flight. If not, the pilot should be sure that at the beginning of the flight the device has plenty of battery power for the time frame needed.

The total time of the pilots and an observation of those times with the complication rate revealed that higher total times correlated with higher failure rates. It is important to note that the pilots were not asked exactly how much of their total flight time was logged while using electronic charts. For example, a pilot in the 250 to 500 hour range could have recently switched to electronic charts and logged more than 240 hours using paper charts. Overheating of the device was the most common factor for electronic chart complications. This is understandable as most small piston powered aircraft used for training do not have air conditioning, and the cockpit is subject to plenty of heat and direct sunlight. When the device overheats, it simply shuts down.

The second highest reported electronic chart complication involved the pilot not having access to a current or applicable chart. Coverage areas must be understood by a pilot operating with electronic charts. If a pilot plans to fly to a particular airport or area, it is the pilot's responsibility to make sure the correct and current charts are on board.

The survey results indicated that $68 \%$ of pilots using electronic charts in the cockpit reported that they carry backup charts that were also electronic charts. If an iPhone has the same software installed as the device used then it could be suitable as a backup chart and this could indicated why so many pilots stated that they have electronic back up charts. As indicated in the results section, many of the participants were not comfortable using mobile phones to access essential navigation information. However, in the case that the primary device fails, the survey results indicate that these pilots would use a mobile phone if necessary as a backup source for electronic charts. 
There are many reasons as to why a pilot may or may not use electronic charts. The results of this survey indicated that eight of the 16 applicable participants (50\%) did not use electronic charts did not because they did not own a capable personal device. These students continue to require training and education on paper charts. Initial training using paper charts was indicated as a common reason why pilots did not use electronic charts. One participant indicated that his/her flight instructor did not allow the use of electronic charts prior to earning the private pilot rating. Individual flight instructors may choose to train their students as they see fit.

\section{Conclusion and Recommendations for Further Research}

This research indicates that the majority of pilots currently in training are using electronic charts. The charts are being used for many purposes at all levels of training. More specifically, the devices and software being used have only small variations. Specific limitations were identified as well. Educators and pilots should be aware of these limitations prior to using electronic charts in the classroom or in flight.

It is likely that many pilot students (at universities and otherwise) are not receiving adequate instruction on the software they are using. This research identified common devices and software used at this particular university. Training is required in a number of topic areas for certain pilot certificates, and electronic chart software must also be completely understood by the pilots in training. An organized approach to implementing integrating electronic charts into the curriculum is highly recommended. This should allow for individual UAA institutions to develop preferred software and devices as necessary.

Additional research is suggested in many areas including (1) connectivity to $3 \mathrm{G} / 4 \mathrm{G}$ service while flying, (2) acquisition of current weather data during flight, (3) compass deviation caused by the devices, (4) affordability of IFR electronic charts versus IFR paper charts with numerous providers, and (5) battery life depending on the type of usage. Another research question should be addressed: will current students benefit from using electronic charts during university training when they have a high chance of seeing electronic charts in their professional flying careers? 


\section{References}

American Airlines. (June 24, 2013). American Airlines Completes Electronic Flight Bag Implementation. Retrieved on May 5, 2014 from http://hub.aa.com/en/nr/pressrelease/american-airlines-completes-electronic-flightbagimplementation

Apple. (2014). iPad Air. Retreived on May 18, 2014 from http://www.apple.com/ipad-air/

Arch, D., \& Sherman, M., (2006). The Use of Technology in Collegiate Aviation Programs. Collegiate Aviation Review, 24(1), 9-24.

Berrett, P. (2014). iPad Document Management Systems for Pilots. Professional Pilot Magazine, 48(5), 96-98.

Bhana, H. (2010). Correlating Boredom Proneness and Automation Complacency in Modern Airline Pilots. Collegiate Aviation Review, 28(1), 9-23.

Clark, J. (2014). The Question of Automation. The Professional Flight Instructor Mentor, $16(3), 18-20$.

Croft, J. (2010). Taking the tablets. Flight International. Retrieved on May 10, 2014 from http://www.flightglobal.com/news/articles/tecnam-na-taking-the-electronic-flightbag-to-the-next-348456/

FAA Education and Research (2006). Industry Training Standards. Retrieved May 10, 2014 from http://www.faa.gov/education_research/training/fits/

Federal Aviation Administration. (2014). Current Federal Aviation Regulations.

Retrieved May 20, 2014 from http://www.ecfr.gov/cgibin/textidx?SID=d2aba10f92e975fadb35e150e447a0b2\&node=14:2.0.1.3.10.2.4.2\&r gn $=\operatorname{div} 8$

ForeFlight LLC, (2014). Simple Plans and Pricing. Retrieved on May 10, 2014 from http://www.foreflight.com/pricing/

Moorman, R. (2013) Going Paperless. Air Transport World, 50, 60.

Renzo Jr., J. \& Bliss, T. (2010). The Impact of Transition Training on Adapting to Technically Advanced Aircraft at Regional Airlines: Perceptions of Pilots in Training and Instructor Pilots. Collegiate Aviation Review, 28(1), 42-54. 
Sportsman's Martket, Inc. (2014). Sporty's Pilot Shop. Retrieved on May 15, 2014 from http://www.sportys.com/PilotShop/category/735

Sportsman's Martket, Inc. (2014). Sporty's Pilot Shop. Retrieved on May 15, 2014 from http://www.sportys.com/PilotShop/product/9353 